2015-02

\title{
On the verge? Preferential use of road-facing hedgerow margins by bumblebees in agro-ecosystems
}

\section{Furtado Frota, Francisco Gabriel}

http://hdl.handle.net/10026.1/4401

\subsection{7/s10841-014-9744-3 \\ Journal of Insect Conservation \\ Springer Science and Business Media LLC}

All content in PEARL is protected by copyright law. Author manuscripts are made available in accordance with publisher policies. Please cite only the published version using the details provided on the item record or document. In the absence of an open licence (e.g. Creative Commons), permissions for further reuse of content should be sought from the publisher or author. 


\title{
On the verge? Preferential use of road- facing hedgerow margins by bumblebees in agro-ecosystems
}

\author{
Mick E Hanley* \& Joshua P Wilkins \\ School of Biological Sciences, Plymouth University, Drake Circus, Plymouth, PL4 8AA, \\ United Kingdom
}

* Corresponding Author: Mick Hanley

e-mail: mehanley@plymouth.ac.uk

Tel: $+44(0) 1752584631$ 


\section{Abstract}

2 The global pollinator decline is commonly linked to modern intensive farming

3 practices, partly because excessive herbicide and fertilizer use is thought to reduce

4 pollinator food plant availability. This effect is particularly obvious across crop- /non-

5 crop boundaries, but no study has compared pollinator and food plant abundance on

6 adjacent crop- and roadside margins. We compared bumblebee abundance along 30

7 hedgerows in SW England; bordered either side by roads and arable fields (cultivated

8 with wheat, barley, oilseed rape, or beans). Total bumblebee abundance along roadsides

9 was over twice that observed on adjacent crop-facing margins, irrespective of crop type and this general pattern was apparent for three of the five most common bumblebee species, including generalist and specialist foragers. Both the total number of flowering plant species and the floral abundance of three of the five most visited plants was also higher on roadsides; minor variation between crops was localised and unrelated to margin orientation. We conclude that organic farming may offer some advantages for pollinator conservation since it reduces field margin exposure to agro-chemical inputs. However, since conventional farming will remain central to global food production, modifications to current practices (such as the use of wildflower strips) are needed and may have ancillary benefits for pollinators by protecting arable margins from disturbance and agro-chemicals. In addition, the fact that the roadsides were demonstrably better habitats for pollinators and their food plants than field-facing margins underscores the widespread suggestion that roadside verges should be utilised more as a conservation tool to promote pollinator biodiversity.

23 Keywords: agricultural intensification - ecosystem services - environmental stewardship schemes - field margins - pesticides - pollinators 


\section{Introduction}

The global decline of many different insect pollinators is now well established and the potential repercussions for crop and wildflower pollination widely discussed (Ghazoul 2005; Gallai et al. 2009; Potts et al. 2010; Vanbergen et al. 2013). The likely causes of pollinator declines are numerous, but centre around habitat loss and fragmentation (Goulson et al. 2005; Winfree et al. 2009), the direct and indirect impacts of pesticide use (Brittain and Potts 2011; Whitehorn et al. 2012), and related implications for immune-competence and increased susceptibility to disease (Cameron et al. 2011; Whitehorn et al. 2011). Each of these factors can be linked to the recent, large-scale intensification of agricultural production (Vanbergen et al. 2013). Although all insect pollinator groups have been affected to some extent, bees and bumblebees (Bombus species) in particular, are perhaps the most emblematic of the causes and likely consequences of recent pollinator losses. Within the UK for example, three out of the 25 known Bombus species are now extinct and a further eight have experienced major contractions in distribution and abundance (Goulson et al. 2005) and the UK situation is mirrored globally (Goulson and Hanley 2004; Williams and Osborne 2009; Cameron et al. 2011). The loss of any pollinator has potentially negative consequences for effective ecosystem service provision (Ollerton et al. 2011), but by virtue of their ability to pollinate a large proportion of crop plants and wildflowers, and do so in climatic conditions that other pollinators cannot tolerate, bumblebee decline is of particular concern in temperate regions (Goulson 2010).

Recognising that any attempt to halt or reverse bumblebee losses has to be achieved within the context of highly-modified agricultural landscapes, and continued economic and societal pressure to maximise food production, many contemporary conservation 
options focus on modification to existing farming practices. Consequently the subsidy of cultivated wildflower strips and low input pasture to increase food plant availability became successful pillars of agri-environment schemes (Albrecht et al. 2007; Carvell et al. 2007; Breeze et al. 2014). There are however, other ways in which modification of current farming practices can support bumblebees. By virtue of providing a large and concentrated floral resource, mass flowering crops such as oilseed rape (canola), sunflowers, and beans attract and support bumblebees (Westphal et al. 2003; Hanley et al. 2011; Stanley and Stout 2013). Organic farming is frequently associated with increased bumblebee abundance, not only because of reduced toxicological impacts of agro-chemicals on the insects, but also because of the associated increase in the diversity and abundance of food plants (Belfrage et al. 2005; Holzchuh et al. 2007). However, only a relatively small proportion of cultivated land is currently under organic agriculture and the likely future contribution to global food demand is widely debated (Connor, 2008; Seufert et al. 2012). The situation is complicated further as some authors suggest that the link between organic farming and enhanced biodiversity may simply reflect lower crop yield, since some high productivity organic systems appear to be no more beneficial to wildlife than their conventional counterparts (Gabriel et al. 2013; but see Tuck et al. 2014).

As the largest component of semi-natural habitats in Europe and North America (Marshall and Moonen 2002), arable field margins are vital for maintaining bumblebee populations. Even in the most intensively farmed systems, hedgerows, headlands, and ditches provide at least some pollen and nectar forage in addition to opportunities for nesting and hibernation sites (Mänd et al. 2002; Goulson et al. 2008; Hannon and Sisk 2009). Although found in many parts of NW Europe (e.g. the Bocage of Normandy), 
hedgerows are particularly common in the British Isles and feature prominently in UK conservation planning (e.g. Environmental Stewardship Schemes - see Merckx et al. 2009; Staley et al. 2012). There is concern however, that the range of agro-chemicals routinely used in conventional farming impact severely upon the ability of arable field margins to support biodiversity. Pesticide drift is a major problem, not only because insecticides reduce bee survival and growth (Whithorn et al. 2012; Baron et al. 2014), but also because of the negative impact on pollinator food plants (Marrs et al. 1989; Schmitz et al. 2014). The use of inorganic fertilizers also has significant repercussions for the composition of arable margin flora; elevated soil nitrogen levels promoting the growth of highly competitive grasses at the expense of subordinate, herbaceous food plants used by pollinators (Tsiouris and Marshall 1998; De Cauwer et al. 2006; Schmitz et al. 2014).

In addition to providing habitat and corridors for biodiversity however, hedgerows can also act as a filter for agro-chemical inputs. Tsiouris and Marshall (1998) report a dramatic reduction in soil nitrogen concentration from the side of a hedgerow facing an arable field to the opposite 'control' side, while Otto et al. (2009) show a similar effect for pesticides. This effect is however, only likely to be apparent where one side of the hedgerow does not routinely receive pesticide or fertilizer input, a situation most commonly encountered when the arable field borders a road. Using this rationale, Croxton et al. (2002) compared the plant and bumblebee communities either side of hedgerows bordered by arable fields (wheat or oilseed rape) and green lanes (unmetalled tracks used primarily by walkers and horse-riders). They showed that plant species richness and bumblebee abundance were higher on the side adjacent to the green lane, although they recognised that their results may have been partly confounded by the 
97 fact that the central portion of the lane also contains pollinator food plants. Nonetheless, similar variation in the abundance of bee food plants was reported by Henriksen and Langer (2013) when they examined paired road and arable (wheat) margins in Denmark. To date however, no study has compared bumblebee abundance across hedgerows bordering sealed roads and arable fields containing multiple crop types.

The main aim of this study was to test the hypothesis that bumblebee abundance and species composition vary across arable field - road boundaries, irrespective of the crop being cultivated. Although disturbance and exposure to vehicular emissions might be expected to have negative impacts on biodiversity (Forman and Alexander 1998; Spellerberg 1998), many country roads experience relatively low traffic volumes and we hypothesised that by virtue of the presence of hedgerows common in our study region, road verges would offer enhanced forage opportunities for bumblebees. In addition, there is a growing movement to use roadside verges as a means of promoting pollinator habitat and abundance (Hopwood 2008; Noordijk et al. 2009; Wojcik and Buchmann 2012; Skórka et al. 2013) and our study offers a way of assessing the comparative value of roadside verges for pollinators and their food plants.

\section{Materials and Methods}

\section{Study sites}

Bumblebee surveys were carried out over a 5-week period between early June and early-July 2013 in 30 paired arable field and adjacent roadside margins situated in Devon and Cornwall, southwest England (Table S1). All sites were situated amongst intensively farmed, mixed arable and pastoral field systems typical of the region, and were well away from other major land-use types (forestry, upland moorland) and major 
urban conurbations (Plymouth, Torbay, and Exeter). Consequently, it is unlikely that variation in land-use at the landscape-scale had any impact on bumblebee assemblages around our chosen study sites. In addition all fields were between $50 \mathrm{~m}$ and $190 \mathrm{~m}$ absl and we included a mixture of field and (crop-facing) margin aspects in our surveys such that our observations were not biased by field/margin aspect or altitude (Table S1). All margins were centred on long-established (i.e. > 200 years) hedgerows comprised of several native woody plant species; e.g. Corylus avellana L., Crataegus monogyna Jacq. Fraxinus excelsior L., Prunus spinosa L. Rosa canina L., Rubus fruticosus L., and Ulex europaeus L. and which typically possess a naturally colonising, diverse basal flora including Dactylis glomerata L., Digitalis purpurea L., Geranium robertianum L., Heracleum sphondylium L., Ranunculus repens L., Silene dioica (L.) Clairv., Stachys sylvatica L., and Urtica dioca L. Typically both road- and field-facing hedgerows and margins are cut once a year (in mid/late-summer) with little or no other deliberate management. Consequently the trajectory of plant community development either side of field boundaries likely reflects modification of a common basal flora by agrochemical input and disturbance on the field-side and (to lesser extent given low traffic volumes) disturbance and exhaust fume emissions on the road-side.

While we were unable to ascertain a detailed account of pesticide use for study sites, each land-owner confirmed that all arable fields had been in conventional cultivation for several decades and were thus likely to have experienced a long history of exposure to agro-chemicals. In addition, the structural similarity of the field margins, coupled with the fact that all the arable crops we encountered are planted in rotation, means that croptype or associated agro-chemical application within individual farms were unlikely to affect the location and abundance of bumblebee nests or hibernation sites, or plant 

L.), barley (Hordeum vulgare L.), oilseed rape (Brassica napus L.) and field bean (Vicia faba L.), which together account for $46 \%, 23 \%, 18 \%$ and $2 \%$ (by area) respectively of 147 all arable crops grown in the UK (Garthwaite et al. 2012). The use of replicate wheat 148 (9), barley (8), bean (7) and oilseed rape (6) fields also allowed us to compare whether any variation in bumblebee assemblages between field- and roadside margins was linked to crop type. All fields were separated by at least $1 \mathrm{~km}$ to minimize nonindependence of observed bumblebees (Knight et al. 2005; Osborne et al. 2008).

\section{Bumblebee surveys}

153 At each location we monitored bumblebee activity along a $100 \times 2 \mathrm{~m}$ transect set out along the central part of an arable field margin, and matched this with an adjacent roadside margin. UK agricultural policy requires a $1 \mathrm{~m}$ border between the field boundary and the crop edge, and for our arable fields this border was comprised primarily of the perennial herb and grass species associated with the basal flora of the hedgerow. This $1 \mathrm{~m}$ border, plus an additional metre extending to a point approximately half way into the hedgerow proper, formed the $2 \mathrm{~m}$ width of our transects on the arable field margin. All adjacent road-side verges were selected such that $1 \mathrm{~m}$ of verge was available running from the hedgerow base to provide a mirror sample to the arable side.

Transects were walked once between 9:00-17:00 on days favourable to bumblebee activity (Goulson and Darvill 2004). Each transect took approximately 15 minutes to complete, with a 15 minute 'rest' period between sides to limit repeat sampling of individual bees before the adjacent margin was sampled. We identified and recorded all bumblebees observed actively foraging (i.e. actually visiting an inflorescence), together 
with the plants upon which they foraged. Due to the difficulty of separating workers of the subgenus Bombus s. str. (i.e. Bombus terrestris (L.), B. lucorum (L.), B. magnus Vogt. and B. cryptarum (Fabricius) in the field (Williams et al. 2012), we made no attempt to distinguish between these species and throughout refer to this group 171 collectively as $B$. terrestris agg. We made no attempt to capture foraging bumblebees, but because transects were linear and completed relatively rapidly, it is extremely unlikely that the same individual was recorded more than once during each transect walk.

Immediately after completing bumblebee surveys, we estimated the number of flowers of each plant species likely to be visited by bumblebees along each transect to determine variation in floral resource availability between field- and roadside margins. Estimates for total flower number were achieved by counting the number of flowers on 10 separate inflorescences of a given plant species and then to multiply this mean value by 180 the estimated total number of inflorescences observed along the transect. For Asteraceae a capitulum was considered to be a single 'flower'.

Following an Anderson-Darling test for normality and data transformation where appropriate, we compared variation in total bumblebee visitation to road- and crop184 facing margins using a General Linear Model (GLM) with 'margin orientation' and 185 'crop' as factors and the 'margin orientation' $\times$ 'crop' interaction to examine evidence for crop-specific variation in bumblebee response to margin orientation. The same approach was applied individually to each of the five most commonly visited plant species. All analyses were performed in Minitab version 16.0. 


\section{Results}

191 In total we observed 211 bumblebees foraging along hedgerow transects; the majority 192 of which (70\%) were recorded on the roadside margin (Fig 1). We also observed some 193 variation between crops; barley field margins attracting on average over twice the number of bumblebees (mean per transect $=4.9 \pm 0.8 \mathrm{SE}$ ) as beans $(2.4 \pm 0.3)$. A twofactor GLM confirmed the strong effect of 'margin orientation' $\left(F_{1,52}=27.7, P=\right.$ $<0.001)$ and 'crop' $\left(F_{3,52}=4.42, P=0.008\right)$ on bumblebee abundance. However, there was no 'margin orientation' $\times$ 'crop' interaction $\left(F_{3,52}=3.50, P=0.458\right)$, suggesting that the higher abundance of bumblebees on roadside margins remained consistent for all four crops.

The majority of forage visits were made by $B$. terrestris agg. (44.1\% of total bumblebee visits), followed by B. hortorum L. (16.6\%), B. pascourum Scopoli (16.6\%), B. lapidarius L. (11.4\%), B. pratorum L. (9.0\%), and B. hypnorum (L.) (2.4\%). A Chisquare test of association found no significant difference $\left(\chi^{2}=10.58, \mathrm{df}=5, P=0.06\right)$ in the relative frequency of the six Bombus species foraging on roadside or crop-facing margins. Nonetheless, three species (B. terrestris, B. hortorum \& B. pratorum) were more frequent on the road-side margin with none of these yielding a significant 'margin orientation' $\times$ 'crop' interaction (Table 1).

A total of 22 different plant species were visited by bumblebees during the surveys and on average more flowers of these species were available to bumblebees on roadside verges than those facing the crop (Two-factor GLM: 'margin orientation' $F_{1,52}=5.18, P$ $<0.027)$. However, neither the 'crop' $\left(F_{3,52}=2.25, P=0.094\right)$ effect nor the 'margin orientation' $\times$ 'crop' interaction $\left(F_{3,52}=0.71, P=0.533\right)$ were significant (Fig 2$)$. 
The five most frequently visited plant species were Silene dioica (38.4\% of bumblebee visits), Heracleum sphondylium (20.4\%), Geranium robertianum (11.8\%), Digitalis purpurea (9.5\%), and Ranunculus repens (9\%), together accounting for $89 \%$ of all recorded visits. Of these, the flowers of $S$. dioica (two-factor GLM on $\log _{10}$ transformed data $\left.-F_{1,52}=4.69, P=0.035\right), G$. robertianum $\left(F_{1,52}=16.35, P<0.001\right)$, and $R$. repens $\left(F_{1,52}=31.04, P<0.001\right)$ were more abundant on roadside margins (Fig 3). Two species, $G$. robertianum $\left(F_{3,52}=2.91, P=0.043\right)$ and $H$. sphondylium $\left(F_{3,52}=4.78, P=\right.$ 0.005) exhibited variation linked to crop type, likely reflecting the high relative abundance of the former in wheat margins and of the latter in barley. However, none of the five species examined showed any 'margin orientation' $x$ 'crop' interaction, suggesting where plant species had higher floral abundance on roadside margins, the effect was consistent across all crop types.

\section{Discussion}

Our results revealed that foraging bumblebees were more abundant along roadside margins of arable field boundaries; an observation consistent for three of the most common UK bumblebees and including species considered to be both generalist ( $B$. terrestris agg and B. pratorum) and specialist (B. hortorum) foragers. At the same time, road-side margins offered more abundant floral resources for pollinators than the adjacent crop-facing margin. Given the close relationship between forage plant availability and bumblebee abundance (Heard et al. 2007; Hanley et al. 2014), it seems reasonable to conclude that that the higher floral abundance on roadside margins was responsible for elevated bumblebee numbers. Although we made no attempt to quantify soil nitrogen or pesticide, a number of studies have shown marked variation in agrochemical concentrations just meters across arable field margins (Tsiouris and Marshall 
1998; Croxton et al. 2002; Otto et al. 2009). It is likely that there was some deposition of nitrous oxides from car exhausts along our roadside margins, although recent evidence from North America (Bettez et al. 2013; Watmough et al. 2014) suggests that for even busy roads (i.e. a traffic volume of several thousand cars per day), annual roadside nitrogen deposition is at least two orders of magnitude lower than levels associated with agricultural inputs on crop-facing margins (Tsiouris and Marshall 1998). Consequently it likely that the across-hedgerow variation in flowering plant species abundance we observed for relatively low traffic volume countryside roads was linked to variation in soil nitrogen levels (see Tsiouris and Marshall 1998; De Cauwer et al. 2006; Schmitz et al. 2014), although additional impacts of herbicide application and disturbance (ploughing) are probable (Croxton et al. 2002). Indeed, Marrs et al. (1989) showed that the local effects of herbicide spray drift can be lethal for both $S$. dioica and D. purpurea, two of the most important bumblebee forage species observed in our study.

We also found remarkably little between-crop variation for either bumblebee or food plant abundance. Only Bombus terrestris agg exhibited any variation linked to crop type (being more abundant in barley margins) which may itself be explained in part by the higher relative abundance of $H$. sphondylium flowers. Like G. robertianum in wheat, where $35 \%$ of all recorded flowers for all crops were located along four hedgerows, 49\% of all $H$. sphondylium flowers were recorded from five barley margins. Consequently the apparent concentration of $B$. terrestris agg on barley probably reflects local patchiness in forage availability rather than any variation due to the crop type itself (11 of the 18 observations of B. terrestris agg on H. sphondylium were from these sites). The fact that we found no 'margin orientation' $\times$ 'crop' interactions for individual bee or 
plant species highlights the remarkable consistency in our results and corroborates our conclusion that consistently higher floral abundance on roadside margins supported more bumblebees, irrespective of the adjacent crop type.

Although Henriksen \& Langer (2013) also showed that flowers of likely bumblebee food plants were more abundant on the roadside margin of arable field boundaries, they did not investigate the associated impact on the pollinator community. Croxton et al. (2002) did report a positive association between plant and bumblebee communities along track-sides, but their study focussed on green-lanes and investigated just two different crop types (wheat and oilseed rape). Consequently ours is the first study to show how (sealed) roadside margins support comparatively more bumblebees and their food plants in comparison with adjacent crop-facing margins. This is important because unlike green-lanes that offer forage resources within the lane itself, sealed roadside margins offer a more robust control against which to compare the impacts of conventional farming practices on the pollinator assemblages of arable field margins (Croxton et al. 2002).

We recognise that we did not look at landscape- or even farm-scale impacts, but the fact that bumblebee abundance varied so markedly between crop-facing and roadside margins corroborates the widely-held view that conventional farming practices are culpable (in this case via impacts on food plants) for recent pollinator losses (Goulson et al. 2005; Brittain and Potts 2011; Cameron et al. 2011; Vanbergen et al. 2013). Farming policy and practice is changing however. Recent schemes that encourage farmers to cultivate or re-instate the flower-rich hay meadows required by many pollinators (Goulson et al. 2005; 2006) are welcome, but when set against the global demand for food, other options must be considered. Our results corroborate the view that by virtue 
of reduced agro-chemical inputs (and noting that our design eliminates the potentially confounding impacts of crop yield identified by Gabriel et al. (2013)), organic farming could benefit the floral abundance of arable field margins and so promote forage availability for pollinators. Nevertheless, any significant increase in the contribution of organic farming to future global food supply remains in doubt (Connor 2008; Seufert et al. 2012) and modifications to conventional farming methods seem the most likely way to halt further pollinator losses. Due to the widening use of agri-environment schemes, many such measures are already in place, but our results further underscore their potential for pollinator conservation. Wildflower mixtures sown along arable field margins are widely thought to benefit pollinators such as bumblebees by increasing forage availability (Carvell et al. 2007; Pywell et al. 2011), but a further advantage is that they provide a buffer against disturbance and agro-chemical input that may also encourage pollinator-friendly plant species within the permanent field margin (see Kells et al. 2001). Although these measures entail some loss of potential cropping area, further benefits accrue to farmers if a minor reduction in crop yield is compensated by increased pollinator service provision to crops (Breeze et al. 2014; Manning et al. 2014).

Our results also underscore the wider value of roadside verges for pollinator conservation. Not only do roadsides provide refuge from intensive farming practices, when taken together they offer considerable habitat potential; equivalent to over 236,000 Ha in the UK and over 3-million Ha in the USA (Wojcik and Buchmann 2012). It is likely that even without any specific management, much of the available roadside capacity in the UK already provides suitable pollinator habitat; this certainly seems to be the case in our study. Moreover, it must be remembered that in addition to floral 
rewards, in order for them to be attractive to bumblebees roadsides and adjoining areas must also offer nesting and hibernation sites. Again, this is true of our field margins since they were comprised exclusively of mature hedgerows. However, restoring degraded or intensively managed (sub-)urban roadsides to encourage native, flower-rich vegetation could benefit pollinator conservation particularly if nesting and hibernation sites are available.

\section{Acknowledgements}

We thank the land owners for access to their farms and Max Ward, Laura Gould, Sarah Lippett, Matthew Ironmonger, and Alina Tarnawska for help with data collection, and two anonymous referees for comments on an earlier draft of this MS.

\section{References}

Albrecht M, Duelli P, Müller CB, Kleijn D, Schmid B (2007) The Swiss agrienvironment scheme enhances pollinator diversity and plant reproductive success in nearby intensively managed farmland. J Appl Ecol 44:813-822.

Baron GL, Raine NE, Brown MJF (2014) Impact of chronic exposure to a pyrethroid pesticide on bumblebees and interactions with a trypanosome parasite. J Appl Ecol 51:460-469

Belfrage K, Björklund J, Salomonsson L (2005) The effects of farm size and organic farming on diversity of birds, pollinators, and plants in a Swedish landscape. Ambio 34:582-588

Bettez ND, Marino R, Howarth RW, Davidson EA (2013) Roads as nitrogen deposition hot spots. Biogeochem 114:149-163 
Breeze TD, Bailey AP, Balcombe KG, Potts SG (2014) Costing conservation: an expert appraisal of the pollinator habitat benefits of England's entry level stewardship Biodivers Conserv 23:1193-1214

Brittain C, Potts SG (2011) The potential impacts of insecticides on the life-history traits of bees and the consequences for pollination. Basic Appl Ecol 12:321-331

Cameron SA, Lozier JD, Strange JP, Koch JB, Cordes N, Solter LF, Griswold TL (2011) Patterns of widespread decline in North American bumble bees. Proc Natl Acad Sci USA 108:662-667

Carvell C, Meek WR, Pywell RF, Goulson D, Nowakowski M (2007) Comparing the efficacy of agri-environment schemes to enhance bumble Bee abundance and diversity on arable field margins. J Appl Ecol 44:29-40

Connor DJ (2008) Organic agriculture cannot feed the world. Field Crops Res 106: $187-190$

Croxton PJ, Carvell C, Mountford JO, Sparks TH (2002) A comparison of green lanes and field margins as bumblebee habitat in an arable landscape. Biol Conserv $107: 365-374$

De Cauwer, B., Reheul, D., Nijs, I., Milbau, A. 2006. Effect of margin strips on soil mineral nitrogen and plant diversity. Agron Sustain Dev 26: 117-126

Forman, R.T., Alexander, L.E. 1998. Roads and their major ecological effects. Ann Rev Ecol Syst 29: 207-231

Gabriel D, Sait SM, Kunin WE, Benton TG (2013) Food production vs. biodiversity: comparing organic and conventional agriculture. J Appl Ecol 50: 355-364. 
Gallai N, Salles JM, Settele J, Vaissière BE (2009) Economic valuation of the vulnerability of world agriculture confronted with pollinator decline. Ecol Econ 68:810-821.

Garthwaite DG, Hudson S, Barker I, Parrish G, Smith L, Pietravalle S (2013) Pesticide usage survey report 250: Arable crops in Great Britain 2012. DEFRA, London.

Ghazoul J (2005) Buzziness as usual? Questioning the global pollinator crisis. Trends Ecol Evol 20:367-373

Goulson D (2010) Bumblebees: Behaviour, Ecology, and Conservation. Oxford University Press. Oxford.

Goulson D, Darvill B (2004) Niche overlap and diet breadth in bumblebees; are rare species more specialized in their choice of flowers? Apidologie 35:55-64

Goulson D, Hanley ME (2004) Distribution and forage use of exotic bumblebees in South Island, New Zealand. NZ J Ecol 28:225-232

Goulson D, Hanley ME, Darvill B, Ellis JS, Knight ME (2005) Causes of rarity in bumblebees. Biol Conserv 122:1-8

Goulson D, Hanley ME, Darvill B, Ellis JS (2006) Biotope associations and the decline of bumblebees (Bombus spp.). J Insect Conserv 10:95-103

Goulson D, Lye GC, Darvill B (2008) Decline and conservation of bumble bees. Ann Rev Entomol 53:191-208

Hanley ME, Franco M, Dean CE, Franklin EL, Harris HR, Haynes AG, Rapson SR, Rowse G, Thomas KC, Waterhouse BR, Knight ME (2011) Increased bumblebee abundance along the margins of a mass flowering crop: evidence for pollinator spill-over. Oikos 120:1618-1624 
Hanley ME, Awbi AJ, Franco M (2014) Going native? Flower use by bumblebees in English urban gardens. Ann Bot 113:799-806

Hannon LE, Sisk TD (2009) Hedgerows in an agri-natural landscape: potential habitat value for native bees. Biol Conserv 142:2140-2154

Heard MS, Carvell C, Carreck NL, Rothery P, Osborne JL, Bourke AFG (2007) Landscape context not patch size determines bumble-bee density on flower mixtures sown for agri-environment schemes. Biol Lett 3:638-641

Henriksen CI, Langer V (2013) Road verges and winter wheat fields as resources for wild bees in agricultural landscapes. Agric Ecosyst Environ 173: 66-71

Holzschuh A, Steffan-Dewenter I, Kleijn D, Tscharntke T (2007) Diversity of flowervisiting bees in cereal fields: effects of farming system, landscape composition and regional context. J Appl Ecol 44:41-49

Hopwood JE (2008) The contribution of roadside grassland restorations to native bee conservation. Biol Conserv 141:2632-2640

Kells AR, Holland JM, Goulson D (2001) The value of uncropped field margins for foraging bumblebees. J Insect Conserv 5:283-291

Knight ME, Martin AP, Bishop S, Osborne JL, Hale RJ, Sanderson RA, Goulson D (2005) An interspecific comparison of foraging range and nest density of four bumblebee (Bombus) species. Mol Ecol 14:1811-1820

Mänd M, Mänd R, Williams IH (2002) Bumblebees in the agricultural landscape of Estonia. Agric Ecosyst Environ 89:69-76

Manning P, Taylor G, Hanley ME (2014) Bioenergy, food production and biodiversity an unlikely alliance? GCB Bioen 6:DOI: 10.1111/gcbb.12173. 
Marrs RH, Williams CT, Frost AJ, Plant RA (1989) Assessment of the effects of herbicide spray drift on a range of species of conservation interest. Environ Poll $59: 71-86$

Marshall EJR, Moonen AC (2002) Field margins in northern Europe: Their functions and interactions with agriculture. Agric Ecosyst Environ 89:5-21

Merckx T, Feber RE, Riordan P, Townsend MC, Bourn NAD, Parsons MS, Macdonald DW (2009) Optimizing the biodiversity gain from agri-environment schemes. Agric Ecosyst Environ 130: 177-182.

Noordijk J, Delille K, Schaffers AP, Sýkora KV (2009) Optimizing grassland management for flower-visiting insects in roadside verges. Biol Conserv $142: 2097-2103$

Ollerton J, Winfree R, Tarrant S (2011) How many flowering plants are pollinated by animals? Oikos 120:321-326

Osborne JL, Martin AP, Carreck NL, Swain JL, Knight ME, Goulson D, Hale RJ, Sanderson RA (2008) Bumblebee flight distances in relation to the forage landscape. J Anim Ecol 77:406-415.

Otto S, Lazzaro L, Finizio A, Zanin G (2009) Estimating ecotoxicological effects of pesticide drift on nontarget arthropods in field hedgerows. Environ Toxicol Chem 28:853-863

Potts SG, Biesmeijer JC, Kremen C, Neumann P, Schweiger O, Kunin WE (2010) Global pollinator declines: trends, impacts and drivers. Trends Ecol Evol $25: 345-353$ 
Pywell RF, Meek WR, Loxton RG, Nowakowski M, Carvell C, Woodcock BA (2011) Ecological restoration on farmland can drive beneficial functional responses in plant and invertebrate communities. Agric Ecosyst Environ 140:62-67

Schmitz J, Schäfer K, Brühl CA (2014) Agrochemicals in field margins-Field evaluation of plant reproduction effects. Agric Ecosyst Environ 189:82-91

Seufert V, Ramankutty N, Foley JA (2012) Comparing the yields of organic and conventional agriculture. Nature 485:229-232

Skórka P, Lenda M, Moroń D, Kalarus K, Tryjanowski P (2013) Factors affecting road mortality and the suitability of road verges for butterflies. Biol Conserv 159:148-157

Spellerberg IF (1998) Ecological effects of roads and traffic: A literature review. Global Ecol Biogeogr 7:317-333

Stanley DA, Stout JC (2013) Quantifying the impacts of bioenergy crops on pollinating insect abundance and diversity: a field-scale evaluation reveals taxon-specific responses. J Appl Ecol 50:335-344

Staley JT, Sparks TH, Croxton PJ, Baldock KCR, Heard MS, Hulmes S, Hulmes L, Peyton J, Amya SR, Pywell RF (2012) Long-term effects of hedgerow management policies on resource provision for wildlife. Biol Conserv 145:2429.

Tsiouris S, Marshall EJP (1998) Observations on patterns of granular fertiliser deposition beside hedges and its likely effects on the botanical composition of field margins. Ann Appl Biol 132:115-127 
Tuck SL, Winqvist C, Mota F, Ahnström J, Turnbull LA, Bengtsson J (2014) Land-use intensity and the effects of organic farming on biodiversity: a hierarchical metaanalysis. J Appl Ecol 51:746-755

Vanbergen A, The Insect Pollinators Initiative (2013) Threats to an ecosystem service: pressures on pollinators. Front Ecol Environ 11:251-259

Watmough SA, McDonough AM, Raney SM (2014) Characterizing the influence of highways on springtime $\mathrm{NO}_{2}$ and $\mathrm{NH}_{3}$ concentrations in regional forest monitoring plots. Environ Poll 190:150-158

Westphal C, Steffan-Dewenter I, Tscharntke T (2003) Mass flowering crops enhance pollinator densities at a landscape scale. Ecol Lett 6:961-965

Whitehorn PR, Tinsley MC, Brown MJF, Darvill B, Goulson D (2011) Genetic diversity, parasite prevalence and immunity in wild bumblebees. Proc R Soc B 278:1195-1202

Whitehorn PR, O’Connor S, Wackers FL, Goulson D (2012) Neonicotinoid pesticide reduces bumblebee colony growth and queen production. Science 336:351-352

Williams PH, Osborne JL (2009) Bumblebee vulnerability and conservation worldwide. Apidologie 40:367-387

Williams PH, Brown MJF, Carolan JC, Goulson D, An J, et al. (2012) Unveiling cryptic species of the bumblebee subgenus Bombus s. str. world-wide with COI barcodes (Hymenoptera: Apidae). Syst Biodiv 10:21-56

Winfree R, Aguilar R, Vazquez DP, LeBuhn G, Aizen MA (2009) A meta-analysis of bees' responses to anthropogenic disturbance. Ecology 90:2068-2076

Wojcik VA, Buchmann S (2012) Pollinator conservation and management on electrical transmission and roadside rights-of-way: a review. J Pollin Ecol 7:16-26 


\section{$467 \quad$ Figure Legends}

468 Fig. 1. Variation in mean ( \pm SE) bumblebee abundance along $100 \mathrm{~m}$ long 469 transects located either side of adjacent arable field margins (crop-facing versus 470 roadside). Observations were made along $100 \mathrm{~m}$ hedgerow transects situated 471 next to one of four different crop types in 30 conventionally-farmed fields in SW 472 England.

Fig. 2. Variation in mean ( $\pm \mathrm{SE}$ ) abundance of all bumblebee forage plant species along 100m long transects located either side of adjacent arable field margins (crop-facing versus roadside). Observations were made along $100 \mathrm{~m}$ hedgerow transects situated next to one of four different crop types in 30 conventionally-farmed fields in SW England.

Fig. 3. Variation in mean ( \pm SE) floral abundance of the five most frequently used bumblebee forage plants along $100 \mathrm{~m}$ long transects located either side of adjacent arable field margins (crop-facing versus roadside). Observations were made along $100 \mathrm{~m}$ hedgerow transects situated next to one of four different crop types in 30 conventionally-farmed fields in SW England. 
488

Fig 1

489

490

491

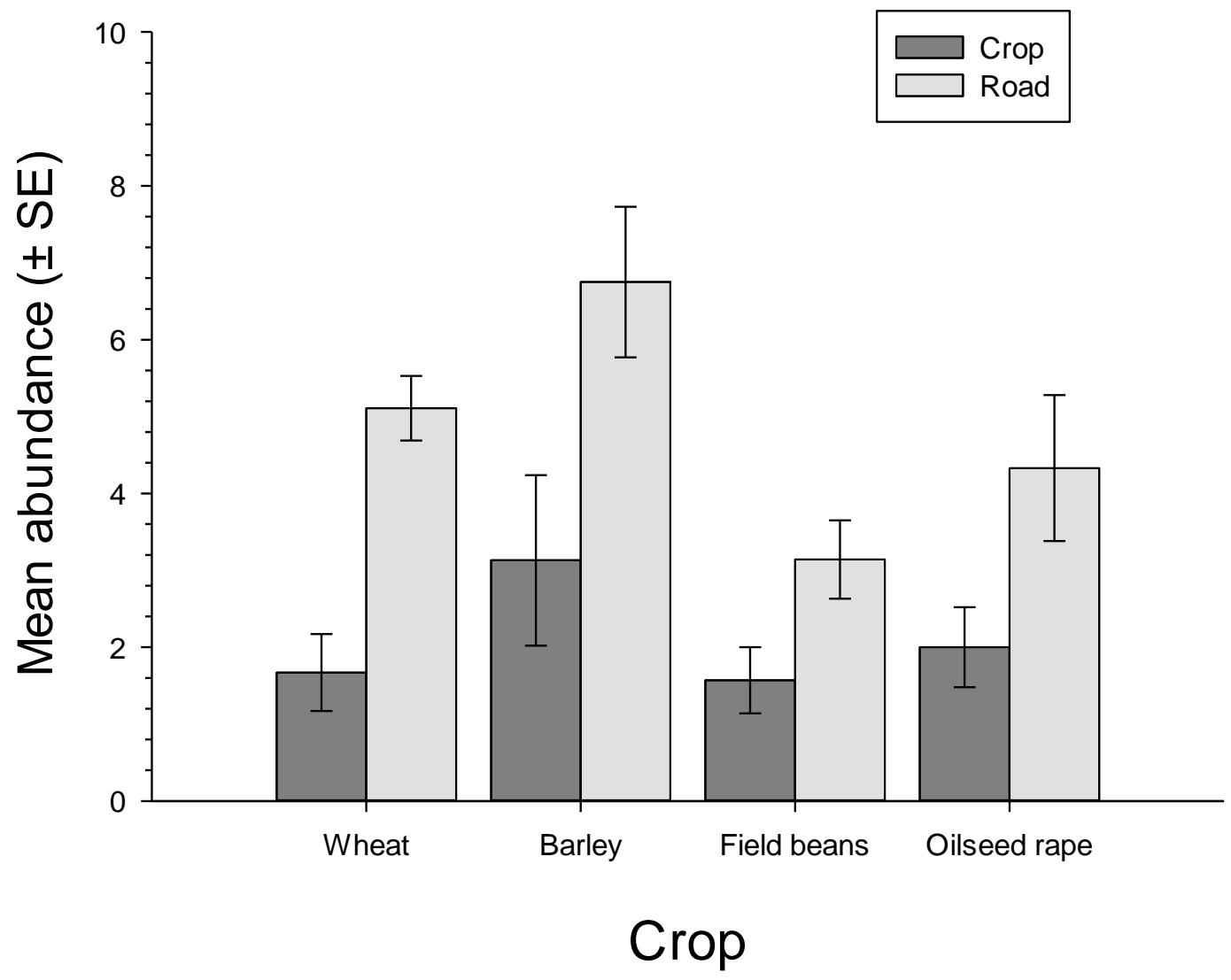

493

494

495

496

497

498

499

500 
$501 \quad$ Fig 2

502

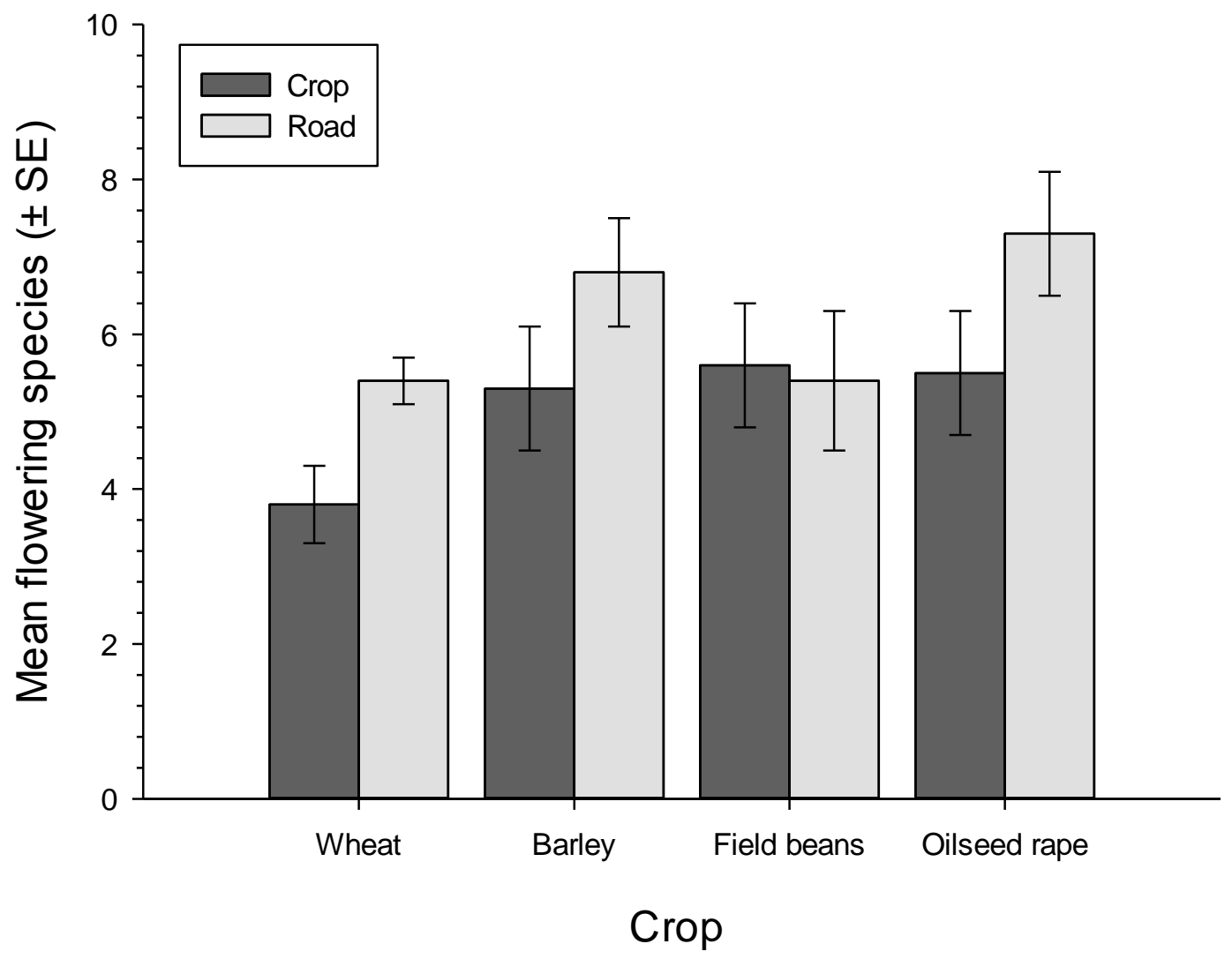

504

505 
Fig 3
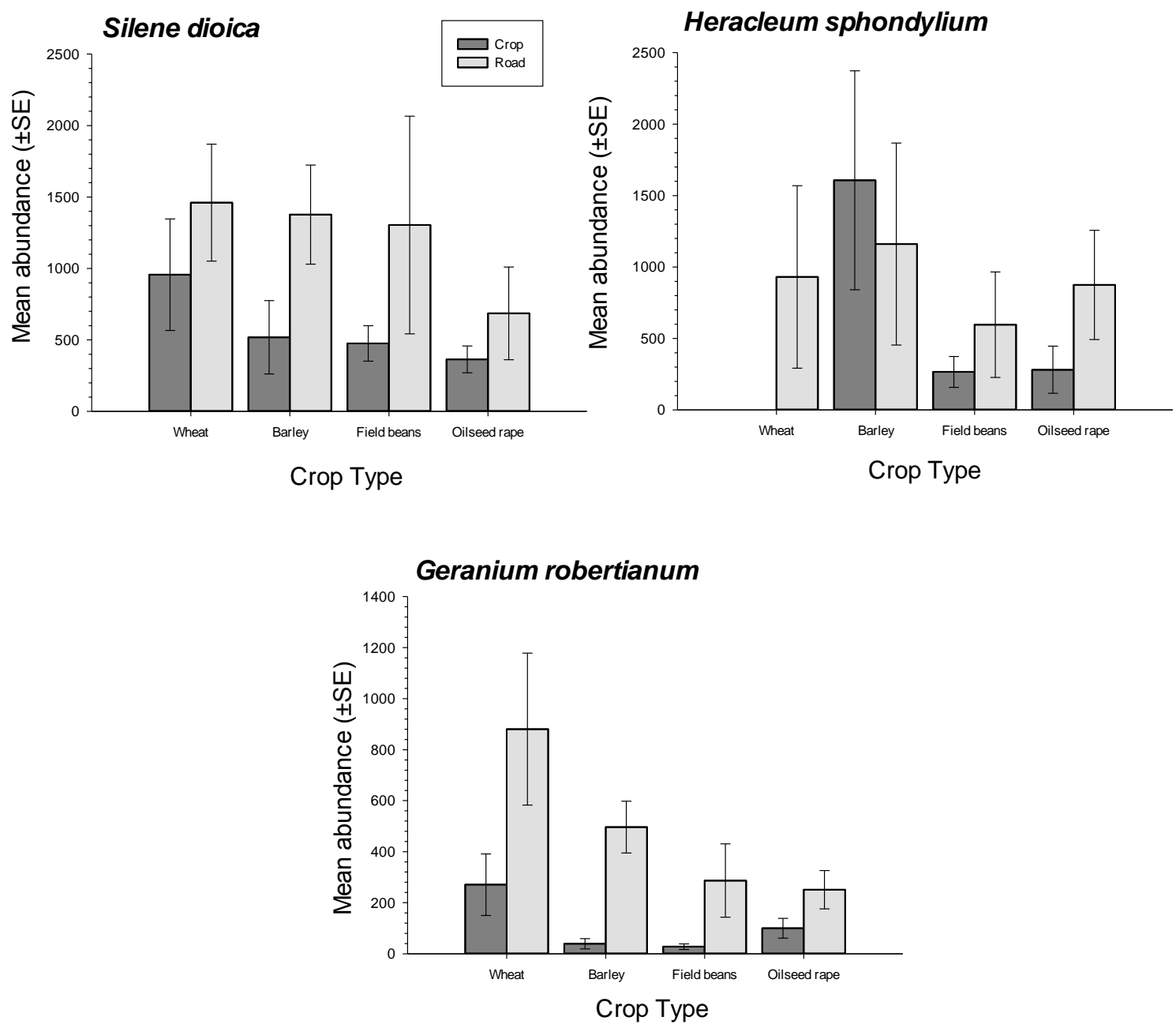

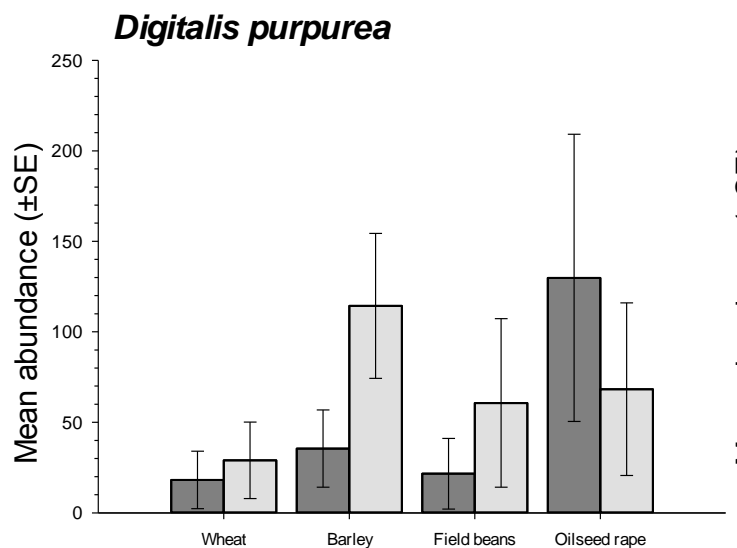

Crop Type

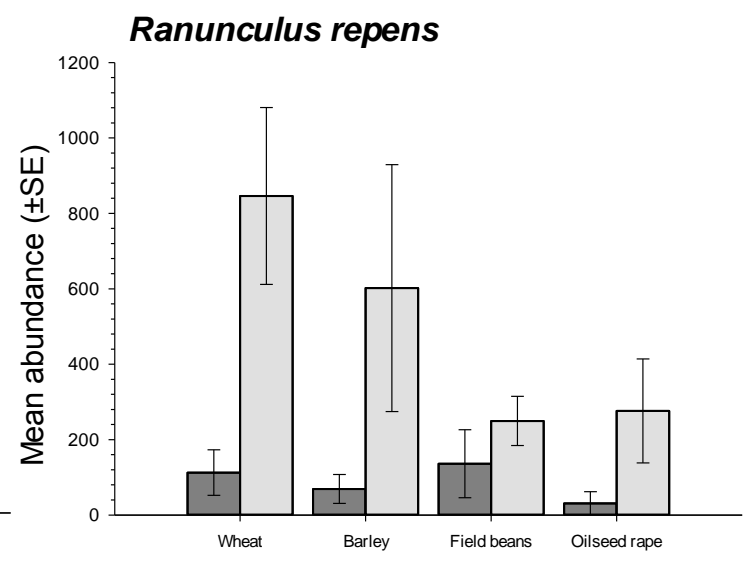

Crop Type 
510

511 Table 1. Variation in mean ( \pm SE) abundance of five bumblebee species observed foraging

512 along adjacent 100m hedgerow transects either side of arable field margins (crop-facing versus

513 roadside) situated next to one of four different crop types in 30 conventionally-farmed fields in

514 SW England. Results of a two-factor General Linear Model examining the interactive effects of

515 margin orientation and crop type are shown; emboldened ' $P$ '-values denote $P<0.05$. In addition

516 to the species shown, a further five individuals of Bombus hypnorum were recorded.

517

\begin{tabular}{|c|c|c|c|c|c|c|c|c|c|c|c|}
\hline \multirow{2}{*}{ Crop } & \multirow{2}{*}{$\begin{array}{c}\text { Margin } \\
\text { orientation }\end{array}$} & \multicolumn{2}{|c|}{$\begin{array}{l}\text { B. terrestris } \\
\text { (93 bees) }\end{array}$} & \multicolumn{2}{|c|}{$\begin{array}{l}\text { B. hortorum } \\
\text { (35 bees) }\end{array}$} & \multicolumn{2}{|c|}{$\begin{array}{l}\text { B. pascourum } \\
\text { (35 bees) }\end{array}$} & \multicolumn{2}{|c|}{$\begin{array}{l}\text { B. lapidarius } \\
\text { (24 bees) }\end{array}$} & \multicolumn{2}{|c|}{$\begin{array}{l}\text { B. pratorum } \\
\text { (19 bees) }\end{array}$} \\
\hline & & Mean & SE & Mean & SE & Mean & SE & Mean & SE & Mean & SE \\
\hline \multirow{2}{*}{ Wheat } & Crop & 0.78 & 0.43 & 0 & 0 & 0.33 & 0.17 & 0.33 & 0.17 & 0.11 & 0.11 \\
\hline & Road & 1.78 & 0.28 & 1.00 & 0.29 & 1.33 & 0.41 & 0.67 & 0.24 & 0.33 & 0.17 \\
\hline \multirow{2}{*}{ Barley } & Crop & 1.38 & 0.53 & 0.50 & 0.27 & 0.75 & 0.41 & 0 & 0 & 0.25 & 0.16 \\
\hline & Road & 3.63 & 0.56 & 1.38 & 0.42 & 0.75 & 0.41 & 0.71 & 0.34 & 0.38 & 0.18 \\
\hline \multirow{2}{*}{ Beans } & Crop & 0.86 & 0.26 & 0.14 & 0.14 & 0.43 & 0.20 & 0.14 & 0.14 & 0 & 0 \\
\hline & Road & 1.43 & 0.20 & 0.29 & 0.18 & 0.29 & 0.18 & 0.14 & 0.14 & 0.83 & 0.44 \\
\hline \multirow{2}{*}{$\begin{array}{l}\text { Oilseed } \\
\text { rape }\end{array}$} & Crop & 0.83 & 0.31 & 0 & 0 & 0.17 & 0.17 & 1.00 & 0.37 & 0 & 0 \\
\hline & Road & 1.50 & 0.56 & 1.33 & 0.76 & 0.33 & 0.21 & 0.33 & 0.21 & 0.83 & 0.31 \\
\hline \multirow{2}{*}{ All crops } & Crop & 3.22 & 1.04 & 0.56 & 0.24 & 1.44 & 0.47 & 1.11 & 0.31 & 0.33 & 0.17 \\
\hline & Road & 7.11 & 1.02 & 3.33 & 0.71 & 2.44 & 0.60 & 1.56 & 0.18 & 1.78 & 0.52 \\
\hline \multicolumn{2}{|c|}{ GLM results } & $F$ & $P$ & $F$ & $P$ & $F$ & $P$ & $F$ & $P$ & $F$ & $P$ \\
\hline \multicolumn{2}{|c|}{ Orientation $\left._{(\mathrm{DF}}=1,52\right)$} & 13.76 & 0.001 & 13.55 & 0.001 & 1.30 & 0.259 & 0.21 & 0.645 & 10.35 & 0.002 \\
\hline \multicolumn{2}{|c|}{$\operatorname{Crop}_{(\mathrm{DF}=3,52)}$} & 4.93 & 0.004 & 1.81 & 0.157 & 1.64 & 0.192 & 1.91 & 0.140 & 0.32 & 0.812 \\
\hline \multicolumn{2}{|c|}{ Orientation $\times \mathrm{Crop}_{(\mathrm{DF}=3,52)}$} & 1.69 & 0.180 & 1.12 & 0.350 & 1.50 & 0.227 & 2.87 & 0.045 & 1.40 & 0.253 \\
\hline
\end{tabular}

